\title{
Requisitos ambientais e acesso a mercados: o setor de defensivos agrícolas
}

\author{
Environmental requirements and market access: \\ the pesticide sector
}

RICARDO K.S. FERMAM*

ADELAIDE ANTUNES**

Rev. Bras. Polít. Int. 51 (2): 26-38 [2008]

\section{Introdução}

A relação entre comércio e meio ambiente reporta-se ao ano de 1970, onde foram reconhecidos seus efeitos e interaçóes, tanto no que diz respeito tanto aos efeitos das políticas públicas afetas ao meio ambiente no comércio como aos efeitos do comércio no meio ambiente.

Em 1972, as preocupaçōes internacionais com os impactos do crescimento econômico no desenvolvimento social e o meio ambiente acarretaram na Conferência sobre o Meio Humano em Estocolmo, no âmbito das Naçóes Unidas. A Secretaria do Acordo Geral sobre Tarifas e Comércio (General Agreement on Tariffs and Trade - Gatt) preparou um estudo, a ser apresentado nesta Conferência, intitulado "Industrial Pollution Control and International Trade", centrado nas repercussões das políticas de proteção ambiental sobre o comércio internacional, refletindo as inquietudes dos países de que tais políticas pudessem converter-se em barreiras ao comércio e constituírem-se numa nova forma de protecionismo - o "protecionismo verde".

Deve ser ressaltado que o Preâmbulo ${ }^{1}$ do Gatt (1947) reconhece a orientação para a mais ampla exploração dos recursos mundiais. Não inclui "meio ambiente" ou "preservação ambiental", mas aborda a proteção da vida e da saúde humana,

\footnotetext{
* Mestre e doutorando em Engenharia Química pela Universidade Federal do Rio de Janeiro (UFRJ) e membro da Gerência de Negociações Regionais do Mercosul - Coordenação Geral de Articulação Internacional do Instituto Nacional de Metrologia, Normalização e Qualidade Industrial - Inmetro (rkfermam@inmetro.gov.br).

** Professora Titular (D.Sc.) do Programa de Pós-graduação em Tecnologia de Processos Químicos e Bioquímicos da Escola de Química da UFRJ (adelaide@eq.ufrj.br).

1 Recognizing that their relations in the field of trade and economic endeavour should be conducted with a view to raising standards of living, ensuring full employment and a large and steadily growing volume of real income and effective demand, developing the full use of the resources of the world and expanding the production and exchange ofgoods. (grifo adicionado pelos autores do presente artigo)
} 
animal e vegetal e a conservação de recursos naturais esgotáveis como exceção e não como obrigação.

Destaca-se, ainda, a publicação do documento "Recomendation of the Council on Guiding Principles Concerning the International Economic Aspects of Environmental Policies", em 1972, pela Organização para a Cooperação e o Desenvolvimento Econômico (OECD, da sigla em inglês). Este documento refletia as preocupações com as implicações das exigências ambientais na competitividade das indústrias dos países membros daquela organização.

Entre os anos de 1971 e 1991, as políticas ambientais começaram a ter um impacto cada vez maior no comércio. Por outro lado, o aumento das correntes de comércio acarretaram efeitos sobre o meio ambiente dos países. Essa situação gerou vários debates. Por exemplo, na Rodada Tóquio² (1973-1979), foi examinada pelos países participantes como as medidas ambientais (sob a forma de normas e regulamentos técnicos) poderiam se constituir em barreiras técnicas ao comércio. Como resultado, foi elaborado o Código de Normas 3 ("Standards Code").

As questôes ambientais relacionadas ao comércio foram novamente abordadas na Rodada Uruguai (1986-1994). Como conseqüência, foram introduzidas modificações no Código de Normas, gerando o Acordo sobre Barreiras Técnicas ao Comércio (Acordo TBT), além da inclusão de várias questôes ambientais no Acordo Geral sobre Comércio de Serviços (General Agreement on Trade and Services - GATS), e os Acordos sobre Agricultura, Medidas Sanitárias e Fitossanitárias (Acordo SPS), dentre outros.

Em 1992, foi realizado na cidade do Rio de Janeiro/Brasil a Conferência das Nações Unidas sobre Meio Ambiente e Desenvolvimento (CNUCED). Os compromissos específicos adotados pela Conferência Rio-92 incluem duas convenções, uma sobre Mudança do Clima e outra sobre Biodiversidade, e também uma Declaração sobre Florestas. A conferência aprovou, igualmente, documentos de objetivos mais abrangentes e de natureza mais política: a Declaração do Rio ${ }^{4}$ e a Agenda 21 (MRE, 2007). Nessa Conferência, especial

2 Rodada multilateral de negociações no âmbito do Gatt. Segundo o art. XXVIII do Gatt, os membros podem decidir se engajar em rodadas de negociação visando a diminuição das tarifas de importação e a abertura dos mercados. No âmbito do Gatt, foram realizadas 8 Rodadas de Negociação: Genebra, Annecy, Torquay, Genebra, Dillon, Kennedy, Tóquio e Uruguai. (MDIC, 2007)

3 O Standards Code estabeleceu certos princípios que informam até hoje as relaçóes comerciais entre os Estados para que seja evitada a criação de barreiras técnicas. Como exemplo, pode-se mencionar o princípio da transparência, segundo o qual os Estados devem dar a máxima publicidade aos seus procedimentos para elaboração e adoção de regulamentos técnicos e procedimentos de avaliação da conformidade, possibilitando a manifestação de qualquer interessado no processo regulatório. (Tanno e Ferracioli, 2003)

4 A Declaração do Rio, ou Declaração do Rio de Janeiro sobre o Meio Ambiente e Desenvolvimento (1992), define os direitos e as obrigaçôes dos Estados em relação aos princípios básicos do meio ambiente e do desenvolvimento. Inclui, entre outras, as seguintes idéias: a incerteza científica não deve adiar a adoção de medidas de proteção ao meio ambiente e os Estados têm o "direito soberano de aproveitar seus próprios recursos" mas sem causar danos ao meio ambiente de outros Estados.

5 A “Agenda 21" é um programa de ação para viabilizar a adoção do desenvolvimento sustentável e ambientalmente racional em todos os países. 
atenção foi dada ao papel do comércio internacional na redução da pobreza e no combate a degradação ambiental. O conceito de "desenvolvimento sustentável" foi estabelecido como o elo entre a proteção ambiental e o desenvolvimento como um todo. (Inmetro, 2007)

No âmbito do capítulo 19 da Agenda 21 - RIO 92 foram criadas seis áreas programáticas para fortalecer os esforços nacionais e internacionais relacionados a gestão ecologicamente saudável dos produtos químicos, que incluem os defensivos agrícolas: avaliação dos riscos; harmonização da classificação e rotulagem dos produtos químicos; troca de informações; programas para redução de riscos; fortalecimento das condições e capacidades nacionais para a gestão de produtos químicos e prevenção do tráfico internacional ilegal de produtos tóxicos e perigosos.

No âmbito da Organização Mundial do Comércio, é criado em 1995 o Comitê sobre Comércio e Meio Ambiente (Committee on Trade and Environment - CTE, em inglês). O mandato do CTE envolve: (WTO, 2007)

- identificar a relação entre medidas comerciais e medidas ambientais, com o objetivo de promover o desenvolvimento sustentável,

- fazer recomendaçōes oportunas sobre se são necessárias modificaçōes das disposições do sistema multilateral do comércio, compatíveis com o caráter aberto, eqüitativo e não discriminatório do sistema.

No programa original (1995) de trabalho do CTE, constam 10 pontos de atuação: (OMC, 2007)

- Pontos 1 e 5 (atualmente objeto de negociaçōes) . Normas comerciais, acordos ambientais e controvérsias. A relação entre as normas do sistema multilateral de comércio e as medidas comerciais contidas nos acordos multilaterais sobre o meio ambiente (AMUMA), e entre seus mecanismos de solução de controvérsias.

- Ponto 2 Proteção do meio ambiente e sistema de comércio. A relação entre as políticas ambientais relacionadas com o comércio e as medidas ambientais que tenham efeitos comerciais significativos e as disposições do sistema multilateral de comercio.

- Ponto 3 (ponto central) . Como se integram os impostos e outras disposiçôes ambientais no sistema. A relação entre as disposições do sistema multilateral de comercio e: a) as taxas e impostos aplicados com fim ambiental; e b) as prescrições aplicadas com fim ambiental aos produtos, com inclusão de normas e regulamentos técnicos e prescriçôes em matéria de envase e embalagem, etiquetagem e reciclagem.

- Ponto 4. Transparência das medidas comerciais utilizadas com fim ambiental. As disposições do sistema multilateral de comércio com respeito à transparência das medidas comerciais utilizadas com fim ambiental. Em 1998 se estabeleceu uma Base de Dados sobre Meio Ambiente (documentos WT/CTE/EDB/* e documentos WT/CTE/W/46, 77, 118,143 e 195) para que a Secretaria da OMC recompile e atualize 
anualmente todas as medidas relacionadas com o meio ambiente que os governos tenham notificado à $\mathrm{OMC}$ ou que tenham sido assinaladas nos exames das políticas comerciais. Isto foi feito como resultado de intensos debates sobre a transparência mantidos no $C T E$ e as recomendaçóes contidas no informe do CTE de 1996 à Conferência Ministerial de Singapura.

- Ponto 6 (ponto central) . O meio ambiente e a liberalização do comércio. $\mathrm{O}$ efeito das medidas ambientais no acesso à mercados, especialmente no que diz respeito aos países em desenvolvimento e os países menos adiantados, e os benefícios resultantes para o meio ambiente da eliminação das restrições e distorções do comércio.

- Ponto 7. Mercadorias cuja venda está proibida no país de origem. A questão da exportação de mercadorias cuja venda está proibida no país de origem, em particular os produtos perigosos.

- Ponto 8. Propriedade intelectual (ponto central). As disposições pertinentes do Acordo sobre os Aspectos dos Direitos de Propriedade Intelectual relacionados com o Comércio (ADPIC).

- Ponto 9. Serviços. O programa de trabalho previsto na Decisão sobre o comércio de serviços e o meio ambiente.

- Ponto 10 (atualmente objeto de negociaçôes) · A OMC e outras organizaçōes. Contribuição aos organismos competentes da $\mathrm{OMC}$ em relação com as disposições apropriadas que hão de ser adotadas no que diz respeito às relações com as organizações intergovernamentais e não governamentais (ONG).

Além dos Acordos da Organização Mundial do Comércio, há cerca de 250 acordos relacionados às questões ambientais. São os chamados Acordos Multilaterais sobre Meio Ambiente (AMUMAs), dos quais cerca de 20 incluem cláusulas que podem afetar o comércio, como o Protocolo de Montreal, relacionado à proteção da camada de ozônio e ao estabelecimento de certos padróes de produção e a Convenção da Basiléia, sobre o movimento transfronteiriço de rejeitos perigosos. (Inmetro, 2007)

Com relação aos defensivos agrícolas, destacam-se pelo menos dois destes Acordos. O primeiro é a "The Rotterdam Convention on the Prior Informed Consent ${ }^{6}$ (PIC) Procedure for Certain Hazardous Chemicals and Pesticides in International Trade". Esta Convenção disponibiliza aos Estados importadores os instrumentos e as informações necessárias para identificar os perigos potenciais e excluir as substâncias químicas que eles não podem gerir com segurança. No caso de um Estado decidir aceitar a importação, para o seu território, de tais substâncias,

6 Prior Informed Consent, PIC, ou seja, providências quanto a se aplicar o princípio de que um produto químico banido ou severamente restringido no território de um Estado, por razões de saúde ou de considerações ambientais locais, não deveria ser colocado no comércio internacional sem o consentimento prévio e baseado num suficiente conhecimento de causa, por parte do país importador. 
a Convenção facilita seu controle prevendo normas de rotulagem, assistência técnica e outras formas de assistência, e impõe aos exportadores a obediência àquelas normas. (Ramina, 2003)

O segundo acordo aplicável é a Convention on the Control of Persistent Organic Pollutants ${ }^{7}$. A Convenção visa limitar a poluição por poluentes orgânicos persistentes $^{8}$ (POP). Define as substâncias abrangidas, mantendo contudo a possibilidade de acrescentar novas substâncias, e as regras relativas à sua produção, importação e exportação. (SCADPlus, 2007)

Uma das questôes debatidas no âmbito do CTE diz respeito a possíveis conflitos entre as regras comerciais estabelecidas nos acordos da OMC e as regras contidas nos AMUMAs. Os governos dos países, ao negociarem os AMUMAs, podem incluir medidas de sançôes comerciais e, com isso, criar direitos de restringir o comércio, enquanto os acordos da $\mathrm{OMC}$ não permite tais medidas.

Assim, os AMUMAs poderiam tornarem-se incompatíveis com o princípio basilar da OMC de não-discriminação conhecido como "tratamento da nação mais favorecida", onde todas as vantagens, favores, privilégios ou imunidades concedidos a um membro devem ser concedidos a produtos similares de todos os demais. Contudo, até a conclusão deste artigo, não foi submetido à $\mathrm{OMC}$ nenhuma controvérsia formal sobre uma medida prevista num acordo multilateral sobre meio ambiente.

\section{Os requisitos ambientais e o acesso a mercados}

Há duas formas básicas de requisitos ambientais. Aqueles que visam assegurar um padrão mínimo ou característica de produto usualmente sob a forma de regulamentos técnicos, como requisitos de produtos ou limites máximos de resíduos (maximum residue limits - MRLs), ou a imposição de requisitos de rotulagem e embalagem. Os requisitos ambientais aplicam-se às fases iniciais do ciclo do produto - processos ou métodos de produção' (process or production methods - PPMs) - bem como às fases posteriores, sob a forma de normas técnicas voluntárias, que podem dar origem à rótulos ambientais (eco-labels).

Os MRLs são estabelecidos após avaliação de estudos de campo conduzidos pelas indústrias de defensivos agrícolas. Nesses estudos, os defensivos são aplicados

7 Promulgados no Brasil, respectivamente, pelo decreto $\mathrm{n}^{\circ}$ 5.360, de 31 de janeiro de 2005 e pelo Decreto Legislativo no 204, de 7 de maio de 2004, cujos títulos são "Convenção sobre Procedimento de Consentimento Prévio Informado para o Comércio Internacional de Certas Substâncias Quimicas e Agrotóxicos Perigosos" e "Convenção de Estocolmo sobre Poluentes Orgânicos Persistentes".

8 Os poluentes orgânicos persistentes são substâncias químicas que, possuindo certas propriedades tóxicas, resistem, contrariamente a outros poluentes, à degradação, o que as torna particularmente nocivas para a saúde humana e o ambiente. Os POPs acumulam-se nos organismos vivos e propagam-se pelo ar, pela água e pelas espécies migratórias e acumulam-se nos ecossistemas terrestres e aquáticos.

9 A noção de processos e métodos de produção é inata à visualização da cadeia produtiva de certo bem: qual é o método de produção, quais são os ingredientes, os aditivos, a embalagem, ou ainda, quais equipamentos e materiais foram utilizados na fabricação de um determinado produto. 
em uma determinada cultura de acordo com as boas práticas agrícolas (BPA), e os níveis remanescentes nos alimentos são determinados. Os MRLs estabelecidos pelo Codex Alimentarius baseiam-se em práticas agrícolas internacionais e visam proteger e preservar a saúde humana, garantindo o comércio internacional de alimentos livres de barreiras com respeito ao parâmetro de resíduos. Entretanto, o nível de resíduos de pesticidas em alimentos depende de fatores agronômicos e climáticos, e muitos países estabelecem seus próprios limites baseados nas boas práticas agrícolas praticadas localmente. (Imoto, 2004)

Paraas empresas exportadoras dos países em desenvolvimento, principalmente às pequenas e médias empresas, os requisitos ambientais para produtos freqüentemente constituem-se em barreiras técnicas ao acesso a mercados. Barreiras técnicas, considerando o estipulado pela Organização Mundial do Comércio, são barreiras comerciais derivadas da utilização de normas ou regulamentos técnicos não-transparentes ou não-embasados em normas internacionalmente aceitas ou, ainda, decorrentes da adoção de procedimentos de avaliação da conformidade não-transparentes e/ou demasiadamente dispendiosos, bem como de inspeções excessivamente rigorosas.(Inmetro, 2007)

Tanto o regulamento técnico, aprovado por órgãos governamentais e de cumprimento compulsório, quanto à norma técnica, aprovado por uma instituição reconhecida e de cumprimento voluntário, podem referir-se aos processos e métodos de produção. Podem também estabelecer características do produto $^{10}$, como função, desempenho, embalagem e etiquetagem ${ }^{11}$.

Para muitos especialistas, o debate acerca dos PPMs é um dos temas centrais na relação entre comércio e meio ambiente. Os vários processos de produção de papel, por exemplo, poderão gerar diferentes impactos ambientais - sobre a diversidade, a vida selvagem, saúde humana, poluição de cursos de água e do ar, além do uso de energia. Diferentes processos poderiam causar diferentes impactos ambientais, como a produção de papel por reciclagem. (Environ. and Trade Handbook, 2005)

Com relação aos processos e métodos de produção, é importante ressaltar que as definiçõoes de "regulamento técnico" e de "norma" são ambíguas, possibilitando o seguinte questionamento: o Acordo TBT controla tanto os regulamentos técnicos e as normas aplicáveis aos processos e métodos de produção manufaturáveis (PPMs product-related), quanto aqueles processos e métodos de produção não detectáveis no produto final - também denominados processos ou métodos de produção não relacionados a produtos (non-product related PPM)?

10 Tais "características" podem se relacionar, inter alia, a composição do produto, ao tamanho, a forma, a cor, a textura, a dureza, a força tensora, a flamabilidade, a condutividade, a densidade, ou a viscosidade.

11 Estes exemplos, fornecidos no Anexo 1 do Acordo sobre Barreiras Técnicas ao Comércio da OMC, indicam que as "características do produto" incluem não somente qualidades intrínsecas do mesmo, mas também "características relacionadas", como os meios de identificação, a apresentação e a aparência de um produto. Note-se que tais características podem ser estabelecidas tanto positiva ("deve possuir/apresentar") quanto negativamente ("não deve possuir/apresentar") consideradas. 
Para melhor compreensão sobre o tema, pode-se considerar o seguinte exemplo. Duas maçãs - uma produzida organicamente e outra produzida com o uso de defensivos agrícolas, cujo resíduo permanece na fruta. Há dois diferentes tipos de PPM, o que ocasionará diferenças nos produtos: o governo poderá elaborar regulamentos fixando os limites máximos de resíduo na maçã. Poderá também exigir inspeções na maçã orgânica para prevenir a entrada no país de pestes (microorganismos, larvas de insetos, etc). Observe que os diferentes PPMs produziram diferenças no produto final. Neste caso, tratam-se de PPMs relacionados a produtos.

A opinião geralmente adotada pela comunidade comercial é de que o Acordo TBT não seria destinado a ser aplicado aos processos e métodos de produção, a menos que o processo ou método de produção fosse relacionado ao produto (detectável no produto final). Entretanto, os membros notificaram alguns processos e métodos de produção não relacionados ao produto ao Comitê de Barreiras Técnicas ao Comércio (Committee on Technical Barriers to Trade, Comitê TBT). Este foi o caso, por exemplo, dos esquemas de rotulagem ambiental baseados na análise do seu ciclo de vida.

O termo Análise do Ciclo de Vida foi traduzido para o português pela ABNT (Associação Brasileira de Normas Técnicas), que é a representante brasileira na ISO. A denominação original, em inglês, é Life Cycle Assessment-LCA. A Análise do Ciclo de Vida foi definida na norma ISO 14040 (1997) "como a compilação e avaliação de entradas e saídas e de potenciais impactos ambientais dos sistemas de produção por todo seu ciclo de vida”. Ressalte-se que o uso da análise de ciclo do vida resulta em rótulos ambientais baseados em processos ou métodos de produção não relacionados a produtos.

De forma geral, as discussões sobre os efeitos dos requisitos ambientais sobre o acesso a mercados tendem a focalizar sobre os regulamentos técnicos ou normas técnicas relevantes. Os procedimentos que devem ser seguidos para determinar que os requisitos estabelecidos nestas normas e/ou regulamentos são atendidos podem ser difíceis de se cumprir por parte das pequenas e médias empresas dos países em desenvolvimento.

Por exemplo, as tecnologias que tornam possível a avaliação da conformidade de um produto a um determinado requisito ambiental pode ter um alto custo. Por outro lado, quando a conformidade a um processo ou método de produção deve ser avaliado, o custo da certificação e as condições que devem ser atendidas pelo organismo de certificação para ser reconhecido ou acreditado no país importador, podem se constituir em dificuldades extras para o país exportador.

Noutras palavras, o exportador pode não possuir a capacidade tecnológica necessária para comprovar que o seu produto atende aos requisitos técnicos países importadores. A implementação e avaliação da conformidade requer sistemas de monitoramento e o acesso a infra-estrutura laboratorial e metrológica. Com relação aos defensivos agrícolas, os problemas que freqüentemente ocorrem 
referem-se a determinação dos resíduos destas substâncias - quando o importador fixa o limite do resíduo próximo ao limite de detecção da substância ${ }^{12}$.

Uma avaliação dos níveis residuais de defensivos em produtos é extremamente importante para referenciar os produtores quanto às boas práticas agrícolas e, caso estas não estejam sendo seguidas, permitir a tomada de medidas preventivas e de controle antes que resíduos destes contaminantes químicos afetem o meio ambiente e a saúde da população ou causem graves perdas econômicas.

Por ser muito elevado o número de defensivos utilizados nos alimentos, por se encontrarem em concentraçôes muito baixas (da ordem de $\mathrm{mg} / \mathrm{kg}$ ), e também poderem estar presentes em uma grande variedade de matrizes, cada uma com suas particularidades, a identificação e a quantificação destas substâncias nos alimentos torna-se extremamente complexa, não obstante, a exigência no mercado internacional, com os níveis de resíduos de contaminantes cada vez menores, é crescente. (Relatório final, 2007)

De fato, os requisitos ambientais compulsórios, expressos sob a forma de regulamentos técnicos, são cada vez mais freqüentes. De acordo com o Banco de Dados Ambientais da OMC, que contém informaçōes acerca de requisitos ambientais emitidos por órgãos governamentais, em 2003 foram notificados à OMC 247 regulamentos técnicos relativos ao meio ambiente. Entre os Acordos constitutivos da OMC, os Acordos TBT e SPS ${ }^{13}$ tiveram o maior número de notificações sobre exigências técnicas ambientais (100 e 51, respectivamente), um total de $40,5 \%$ e $20,6 \%$ de todas as notificações sobre o tema. (WTO, 2007)

\section{Conclusões}

A questão ambiental, relacionada ao comércio internacional está cada vez mais presente, influenciando processos e cadeias produtivas, alterando a competitividade e o acesso a mercados. Nos fóruns internacionais, tanto na área ambiental como comercial (OMC, Mercosul, etc), crescem os debates quanto a natureza e riscos potenciais de produtos fabricados, degradação ambiental, barreiras (técnicas e sanitárias) ao comércio, discriminação de produtos com base nos processos de fabricação e aplicação de regras internacionais de proteção ao patrimônio comum.

Assim, os produtos do agronegócio brasileiro, sobretudo os mais competitivos, enfrentam forte protecionismo nos mercados externos. Em geral, este protecionismo pode ser de dois tipos: barreiras tarifárias (picos tarifários ${ }^{14}$,

12 Este caso é particularmente comum quando o defensivo em questão é um complexo composto orgânico (inseticidas, por exemplo) que deve ser medido por sofisticados (e caros) equipamentos de laboratório operados por técnicos altamente qualificados.

13 Acordo sobre Aplicação de Medidas Sanitárias e Fitossanitárias da OMC.

14 Os picos tarifários são tarifas muito acima da média das demais tarifas de um determinado país. 
escaladas tarifárias ${ }^{15}$, quotas tarifárias, salvaguardas agrícolas especiais, etc.) e as barreiras não-tarifárias (barreiras técnicas, fitozoosanitárias, subsídios, etc.).

De maneira geral, as exigências técnicas adotadas para produtos do agronegócio nos países desenvolvidos são bem mais rigorosos que os prevalecentes em países em desenvolvimento, envolvendo custos mais elevados. Além disso, as exigências referentes a aspectos de segurança e qualidade destes produtos têm-se alterado com freqüência, devido à maior velocidade com que novas tecnologias são desenvolvidas e adotadas, tanto para a obtenção de produtos mais adequados ao consumo, como para o controle da qualidade desses produtos nos vários estágios de produção, processamento e comercialização. (Oliveira, 2005)

Tais exigências encontram-se relacionadas à diversos "elos" da cadeia produtiva do agronegócio, em especial aos insumos provenientes da indústria química, como os defensivos agrícolas. Limites máximos de resíduos, métodos e processos de produção, tipos de substâncias permitidas ou proibidas, rotulagem, dentre muitas outras exigências técnicas, por parte dos países importadores, acabam produzindo barreiras comerciais, não só destas substâncias per si, mas também dos produtos do agronegócio, principal usuário destas substâncias.

Por exemplo, em diversos estados indianos foram proibidas as vendas da Coca-Cola e da PepsiCo, por terem sido encontrados resíduos de defensivos, nestas bebidas, acima16 do limite estabelecido na legislação daquele país (NYTIMES, 2006). Outro exemplo refere-se à lista de ingredientes ativos, publicada recentemente pela Comunidade Européia (CE), para resíduos de defensivos nos produtos agrícolas importados pelo bloco. Para se ter uma idéia do impacto desta medida, no caso da citricultura, há no Brasil 108 ingredientes ativos produzidos e autorizados para uso e a nova lista da $\mathrm{CE}$ reduz este número para 56 ingredientes ativos, dos quais 37 estão regularizados e 19 à espera de informaçōes dos grupos detentores de suas moléculas17.

Muitos dos defensivos agrícolas que as naçōes industrializadas baniram ou restringiram, ainda são usados largamente nos países em desenvolvimento, e os defensivos que são exportados aos países em desenvolvimento são freqüentemente usados por produtores incapazes de ler as instruçōes nos rótulos e avisos de precaução.

A atividade produtiva em todo o mundo tem se tornado cada vez mais regulada por normas ambientais que estabelecem parâmetros para a produção, como a ISO 14000. O atendimento a essas normas já se tornou requisito básico à atuação no comércio internacional. Assim, se o Brasil quiser competir em

15 Escaladas tarifárias ocorrem quando um país aplica suas tarifas de importação de acordo com o estágio de processamento do produto importado, isto é, tarifas mais baixas para insumos básicos e mais elevadas para produtos semi-acabados e finais. Essa prática acaba por desestimular as exportações de produtos com maior valor agregado e, consequentemente, a indústria de transformação no país exportador. (Fiesp, 2006)

16 Conforme o Jornal Online Hindustan Times, foram encontrados nas amostras resíduos de defensivos na concentração de 11,85 partes por bilhão (ppb), 24 vezes acima do limite permitido.

17 Dos ingredientes hoje autorizados, alguns não são mais fabricados e outros são pouco usados. (Valor, 2006) 
igualdade de condições com os países mais desenvolvidos, é fundamental que seja incorporado imediatamente, pelo país, uma nova cultura empresarial, com foco na gestão ambiental. Além de atenuar os impactos da ação do homem sobre o planeta, o uso ponderado dos recursos naturais já é fator determinante para a competitividade mundial.

Por outro lado, o comércio internacional de produtos e tecnologias environmental-friendly é claramente dominado por países desenvolvidos, que possuem legislações ambientais eficazes. Isso faz com que o fluxo de comércio destes produtos seja preferencialmente deslocado para os países desenvolvidos. Assim, estes países serão, claramente, preceptores dos grandes benefícios de uma eventual liberalização comercial.

Como pode ser facilmente observado, estes casos estão fortemente baseados na análise do ciclo de vida (ACV) dos produtos, isto é, no estudo de seus efeitos ambientais desde o momento de sua produção até o de sua eliminação definitiva e, posteriormente, nos processos e métodos de produção de cada produto. Por outro lado, torna-se altamente relevante a metrologia química, por exemplo na determinação dos limites de defensivos nos produtos, e a avaliação da conformidade ${ }^{18}$, por exemplo na rotulagem baseada na ACV dos produtos. Assim, é possível antever o surgimento de exigências técnicas, relacionadas à cadeia de avaliação da conformidade, com relação aos defensivos agrícolas.

É muito importante que as empresas que compõem o setor de defensivos agrícolas busquem conhecer previamente as exigências ambientais dos países desenvolvidos, de forma que possa buscar adequar sua linha de produção às exigências de tais mercados. Para tanto, é possível usar as ferramentas já existentes e amplamente disponíveis, como a base de dados do Ponto Focal de Barreiras Técnicas ao Comércio, do Inmetro, e a base de dados e os estudos elaborados pelo Sistema de Informação sobre a Indústria Química ${ }^{19}$ (Siquim), da Escola de Química da UFRJ.

Por outro lado, é necessário que haja uma maior coordenação dos órgãos brasileiros responsáveis, direta ou indiretamente, pela regulamentação e registro destas substâncias, bem como a notificação. Faz-se mister que cada vez mais os regulamentos técnicos brasileiros estejam baseados em normas internacionais, como a ISO e Codex Alimentarius, além da necessidade do uso de boas práticas

18 É definida como o processo sistematizado, acompanhado e avaliado, de forma a propiciar adequado grau de confiança de que um produto, processo ou serviço, ou ainda um profissional, atende a requisitos pré-estabelecidos em normas e regulamentos técnicos com o menor custo para a sociedade. No Brasil, são adotados os seguintes mecanismos de avaliação da conformidade: Certificação, Declaração do Fornecedor, Etiquetagem (ou rotulagem), Inspeção e Ensaios.

19 O Siquim é constituído de bases de dados de setores e segmentos do complexo químico, como a química fina (fármacos, defensivos, corantes, pigmentos, aditivos e cosméticos), petroquímica, carboquímica, alcoquímica e de derivados de produtos naturais. Os dados, provenientes de informaçôes industriais e tecnológicas, devidamente tratados, são capazes de gerar estudos prospectivos para as diferentes cadeias produtivas, fornecendo subsídios à formulação de políticas públicas para os setores produtivos e suporte à tomada de decisôes por parte das empresas, a partir da construção de mapas de conhecimento. (Siquim, 2007) 
regulatórias para elaboração destas exigências. Quanto ao registro dos defensivos agrícolas, as regras nacionais precisam assegurar às empresas brasileiras, sem o prejuízo da saúde pública e meio ambiente, vantagens competitivas frente às empresas localizadas nos países desenvolvidos.

Com relação aos órgãos notificadores dos regulamentos técnicos brasileiros à $\mathrm{OMC}$, várias alternativas poderiam ser adotadas no afã de disponibilizar às empresas do setor de defensivos agrícolas as informaçóes sobre as exigências técnicas dos países desenvolvidos. Por exemplo, poderia ser criado um Núcleo de Informações, com pessoal técnico altamente qualificado em Comércio Exterior e em toda a cadeia de Defensivos, que seria responsável não apenas por encaminhar aos exportadores as exigências, mas principalmente a análise técnica das mesmas, propondo soluções e alternativas às mesmas.

Recebido em 3 de agosto de 2007

Aprovado em 15 de maio de 2008

\section{Referências Bibliográficas}

Convenção de Estocolmo sobre Poluentes Orgânicos Persistentes. Decreto Legislativo No 204, de 7 de maio de 2004. Disponível na internet em http://www.mct.gov.br/upd_ blob/0012/12505.pdf. Arquivo consultado em 2007.

Convenção sobre Procedimento de Consentimento Prévio Informado para o Comércio Internacional de Certas Substâncias Químicas e Agrotóxicos Perigosos. Decreto No 5.360 de 31 de Janeiro de 2005. Presidência da República. Casa Civil. Subchefia para Assuntos Jurídicos. Disponível na internet em http://www.planalto.gov.br/CCIVIL_03/_Ato2004-2006/2005/ Decreto/D5360.htm. Arquivo consultado em 2007.

Environment and Trade: A Handbook - 2nd Edition. The United Nations Environment Programme (UNEP). Division of Technology, Industry and Economics. International Institute for Sustainable Development (IISD). 2005. Book, 142 pages.

Fiesp. A Rodada de Doha da OMC: Negociaçōes Internacionais. Departamento de Relaçōes Internacionais e Comércio Exterior da Fiesp (DEREX). Disponível em http://www.fiesp. com.br/derex/negociacoes_internacionais/pdf/Cartilha\%20Rodada\%20Doha.pdf. Arquivo consultado em 2007.

Hindustan Times. Pesticide cocktail in Coke, Pepsi brands, says study. Disponível em http:// www.hindustantimes.com/news/181_1759160,0006.htm. Arquivo consultado em 2006.

Imoto, Marvina Natsue. Validação de Método Multiresíduo para Pesticidas Organohalogenados em Maçã por Cromatografia Gasosa com Captura de Elétrons (CG/ECD) e Cromatografia Gasosa com Espectrometria de Massa (CG/MS). Dissertação de mestrado. Programa de Pósgraduação em Tecnologia de Alimentos. Departamento de Engenharia Química. Universidade Federal do Paraná. 2004.

Inmetro. Barreiras Técnicas às Exportaçōes: o que são e como superá-las. Disponível na internet em http://www.inmetro.gov.br/barreirastecnicas/Manual_BarrTecnicas.pdf. Arquivo consultado em 2007. 
Martinelli, Orlando. Relatório Setorial - Final. Setor de Agroquímicos. Finep. 17/11/2005. Disponível na internet em http://www.finep.gov.br/PortalDPP/relatorio_setorial_final/ relatorio_setorial_final_impressao.asp?lst_setor=24. Arquivo acessado em fevereiro de 2007.

MDIC. Ministério do Desenvolvimento, Indústria e Comércio Exterior. Disponível em http:// www.desenvolvimento.gov.br/sitio/secex/negInternacionais/omc/gattRodNegociacao.php. Arquivo consultado em 2007.

MRE. Ministério das Relações Exteriores. Disponível em http://www.mre.gov.br/cdbrasil/ itamaraty/web/port/relext/mre/agintern/meioamb/index.htm. Arquivo consultado em 2007.

Ramina, Larissa. Análise da Convenção de Roterdã Sobre o Procedimento de Consentimento Prévio Informado para o Comércio Internacional de Certas Substâncias Químicas e Agrotóxicos Perigosos: "Convenção Pic". Cadernos da Escola de Direito e Relaçôes Internacionais da UniBrasil. Jul/dez 2003.

Revista do Fundecitrus. ano XXII, no 133, março/abril 2006. páginas. 14 a 16. Disponível em http://www.fundecitrus.com.br/revista/fundec_ed133_pg14a16.pdf. Arquivo consultado em 2006.

SCADPlus. Eliminar e limitar a produção, a utilização e a libertação de poluentes orgânicos persistentes (POP). Comunidades Europeias, 1995-2007. Disponível em http://europa.eu/ scadplus/leg/pt/lvb/121279.htm. Arquivo consultado em 2007.

SDP. Secretaria de Desenvolvimento da Produção. Fórum de Competitividade de Agroquímicos, reunião realizada no dia 19 de abril de 2006. Nota Técnica no 47/06/CGTP/DESIT/SDP. Ministério do Desenvolvimento, Indústria e Comércio Exterior. 20/6/2006.

Siquim. Sistema de Informação sobre a Indústria Química. Disponível na internet em http:// www.eq.ufrj.br/links/siquim/index.html. Arquivo consultado em 2007.

Tanno, Grace e Ferracioli, Paulo. Barreiras Técnicas: o papel do Inmetro do Gatt à OMC. Janeiro de 2003. Disponível na internet em http://www.inmetro.gov.br/infotec/artigos/docs/2. pdf. Arquivo consultado em 2007.

The New York Times (NYTIMES). Pesticide Charge in India Hurts Pepsi and Coke. Disponível em http://www.nytimes.com/2006/08/22/business/22cnd-coke.html?ref=world. Arquivo consultado em 2006.

Valor Econômico Online. Sai uma nova lista de defensivos permitidos. 8/6/2006. Disponível na internet em http://www.valoronline.com.br/valoreconomico/285/agronegocios/179/Sai+u ma+nova+lista+de+defensivos+permitidos,Defensivos\%20Agr\%c3\%adcolas,,179,3729048. html. Arquivo consultado em 2006.

WTO. World Trade Organisation. Committee on Trade and Environment - Environmental Database for 2003 - Note by the Secretariat. WT/CTE/EDB/3. Disponível na internet em http://docsonline.wto.org/. Arquivo consultado em 2007.

WTO. World Trade Organisation. World Trade Organisation. Disponível na internet em http://www.wto.org. Arquivo consultado em 2007.

\section{Resumo}

Os requisitos ambientais do comércio internacional são freqüentemente usados pelos países desenvolvidos como barreiras técnicas ao acesso a mercados pelos países em 
desenvolvimento. Conhecer estes requisitos é especialmente importante para o setor de defensivos agrícolas (pesticidas). Assim, este artigo busca identificar os principais requisitos ambientais relativos aos defensivos agrícolas, mostrando a importância dos mesmos para os comércio exterior dos países em desenvolvimento, especialmente o Brasil.

\section{Abstract}

The environmental requirements of the international trade are frequently used for the developed countries as technical barriers to the market access for the developing countries. To know these requirements is especially important for the sector of agricultural defensives (pesticides). Thus, this Article seeks to identify the main environmental requirements regards to the agricultural defensives, showing the importance of the same ones for the foreign trade of the developing countries, especially Brazil.

Palavras-chave: Barreiras técnicas, defensivos agrícolas, comércio internacional, requisitos ambientais.

Key words: Technical barriers, agricultural defensives, international trade, environmental requirements. 